\title{
Quality of Electroless Ni-P (Nickel-Phosphorus) Coatings Applied in Oil Production Equipment with Salinity
}

\author{
Fernando B. Mainier, Maria P. Cindra Fonseca, Sérgio S. M. Tavares, Juan M. Pardal \\ Escola de Engenharia, Universidade Federal Fluminense (UFF), Niterói, Brazil \\ Email: fmainier@uol.com.br, mcindra@vm.uff.br, ssmtavares@terra.com.br, juan@vm.uff.br
}

Received August 9, 2013; revised September 9, 2013; accepted September 16, 2013

Copyright (C) 2013 Fernando B. Mainier et al. This is an open access article distributed under the Creative Commons Attribution License, which permits unrestricted use, distribution, and reproduction in any medium, provided the original work is properly cited.

\begin{abstract}
The corrosion resistance of nickel-phosphorus (Ni-P) coatings and their mechanical properties in seawater have led investigations into the development of new technologies and the replacement of some special alloys in equipment used in oil production, such as valves, tubing, sucker rod joints, pumps, riser, manifolds and subsea Christmas trees. These studies began with Brenner and Riddel who developed, in the 1940s, formulations for Ni-P deposition on carbon steel without using an electric current. Joint deposition of nickel and phosphorus on a metallic surface (carbon steel) without applying an external current is accomplished using cathodic reduction with hydrogen $(\mathrm{H})$ from a reducing agent (sodium hypophosphite) and nickel salts. To assure good performance of a Ni-P coating, the deposit quality must be inspected and evaluated during the chemical deposition process or in the end product. The recommended test parameters are: thickness, layer uniformity, hardness, adhesion, porosity, corrosion resistance and chemical composition of the nickel-phosphorus coating. The purpose of this paper was to investigate the Ni-P coating process, to evaluate the behaviour of Ni-P in a saline environment using aqueous brine (3.5\% - 30\% sodium chloride by mass) and to present possible defects that could compromise the coating.
\end{abstract}

Keywords: Nickel-Phosphorus (Ni-P) Coatings; Corrosion; Petroleum; Test

\section{Introduction}

One of the traditional techniques to maintain the mechanical characteristics of a material in the manufacturing of industrial equipment, primarily using carbon steel or low alloy steels, as well as to make surfaces more resistant to abrasion and corrosion, is without doubt, by applying a specific finish, such electroless nickel-phosphorus plating (Ni-P). The Ni-P coating is deposited on carbon steel without the application of an external electrical current. This feature has therefore led to, directly or indirectly, the development of special tools and new technologies in the area of oil production in a high salinity environment associated with corrosive gases such as $\mathrm{CO}_{2}$ and $\mathrm{H}_{2} \mathrm{~S}$.

Historically, the process of nickel deposition was initiated in 1844 by the work of Wurtz [1,2], who discovered the reduction of $\mathrm{Ni}^{2+}$ ions to metallic porous nickel $(\mathrm{Ni})$, and subsequently by Brenner and Riddel [3], who over one hundred years later developed formulations and practices for Ni-P deposition on carbon steel without the aid of an electric current. Studies by Duncan [4], Cola- ruotolo [5], Mainier et al. [6], Tallinn [7], Weil et al. [8], Mainier and Araújo [9], Delaunois et al. [10], Liu et al. [11] and Baudrand [12] have shown that the rate of growth and application of Ni-P coatings since the 1980s has increased in several industrial sectors.

The performance of this finish has led to its use in various industrial areas such as the production of pulp and paper, plastics, petrochemicals, textiles, automobiles, aeronautics, electronics and food. Also, faced with high corrosivity and the increasing challenges of obtaining petroleum under adverse conditions have driven the oil industry to seek new alternatives in the areas of materials. Ni-P coatings, due to their abrasion and corrosion resistance, have presented excellent performance, mainly in terms of valves, special tools, risers, pumps and production pipes. Figure 1 shows some of these applications in the petroleum industry.

The technical literature and patents concerning nickel deposition processes indicate a wide range of development in terms of new formulations, additives and other co-precipitations with cobalt (Co), boron (B), silicon 
carbide (SiC), Teflon, etc., which will provide new properties to Ni-P coatings and therefore lead to new Industrial applications.

\section{Deposition Process of Nickel-Phosphorus}

The electrochemical deposition process, without the aid of an electric current, is presented in Figures 2 and 3. The process starts with the receipt of parts in quality control where they are formalized according to operational procedures that should assess the following parameters: dimensional analysis, definition and assessment of the constituent materials of the part, rules and procedures of surface preparation (chemical or mechanical cleaning for removal of oxides, oily material or grease), the type of bath to be used, temperature, speed of deposition, thickness, and the nickel/phosphorus ratio, among others.

\section{Mechanism and Properties of Ni-P Deposition}

In the conventional process of nickel electroplating, $\mathrm{Ni}^{2+}$

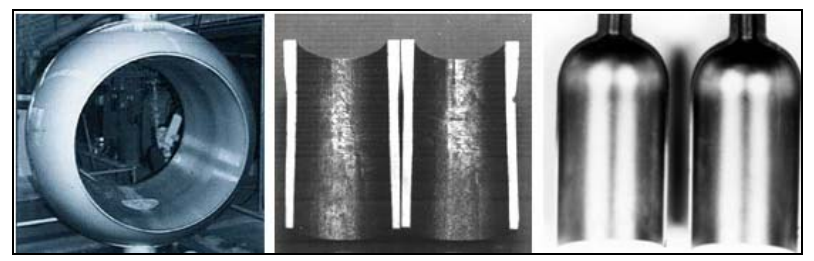

Figure 1. Ni-P coating process in pipeline valve, production pipe and the interior of a corrosive gas storage cylinder.

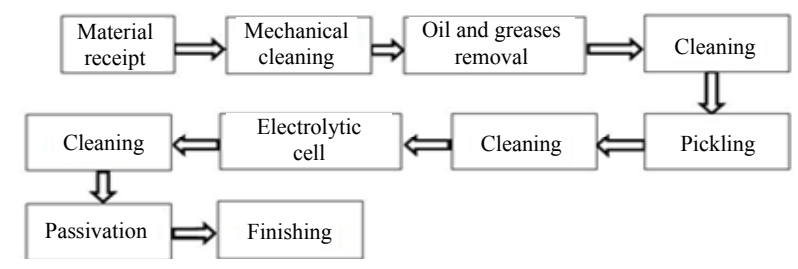

Figure 2. Deposition process.

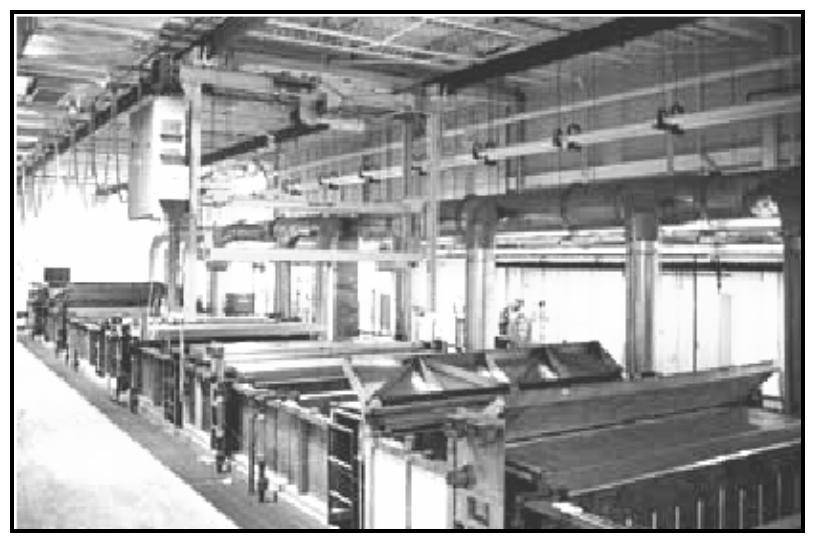

Figure 3. Overview of the bath of nickel-phosphorus. ions (present in the bath) are reduced to metallic nickel by an external electric current and deposited onto the surface of a metallic material connected to the negative pole (cathode), while the positive pole (anode) is usually made up of high purity nickel, as shown in the illustration in Figure 4. The thickness of the deposited nickel film and its properties depend on the electric current density, the voltage in volts applied, the concentration of salts, the bath temperature, $\mathrm{pH}$, the nature of the base metal (cathode) and the additives used to give specific features to the nickel coating.

The first point that differentiates this process is that the deposition of autocatalytic chemical nickel plating requires no external electric current; that is, the process is self-regulated by the kinetics of the reactions involved. Continuous, uniform joint co-deposition of nickel and phosphorus is achieved by cathodic reduction with atomic hydrogen $(\mathrm{H})$ produced in the bath from the hydrolysis of the reducing agent $\left(\mathrm{NaH}_{2} \mathrm{PO}_{2}\right)$. The baths used in the autocatalytic process are more complex and require more control, generally, and are formulated based on nickel salts $\left(\mathrm{Ni}^{2+}\right)$, the reducing agent $\left(\mathrm{NaH}_{2} \mathrm{PO}_{2}\right)$ and additives that control the $\mathrm{pH}$, complexing and the addition of other salts to ensure the quality of the coating [13].

The required scientific and technological knowledge, as well as the reaction mechanisms to explain the deposition of Ni-P, are credited to Gould et al. [14], Duncan [4], Belinsky [15], Mallory [16] and Riedel [17], among others. It can be assumed, on the basis of these authors, that the coating deposition kinetics of Ni-P is based on the following main points and shown in Figure 5.

- Atomic hydrogen capacity formation;

- Hydrogen adsorption capacity by the metal surface;

- Reduction of $\mathrm{Ni}^{2+}$ ions and sodium hypophosphite;

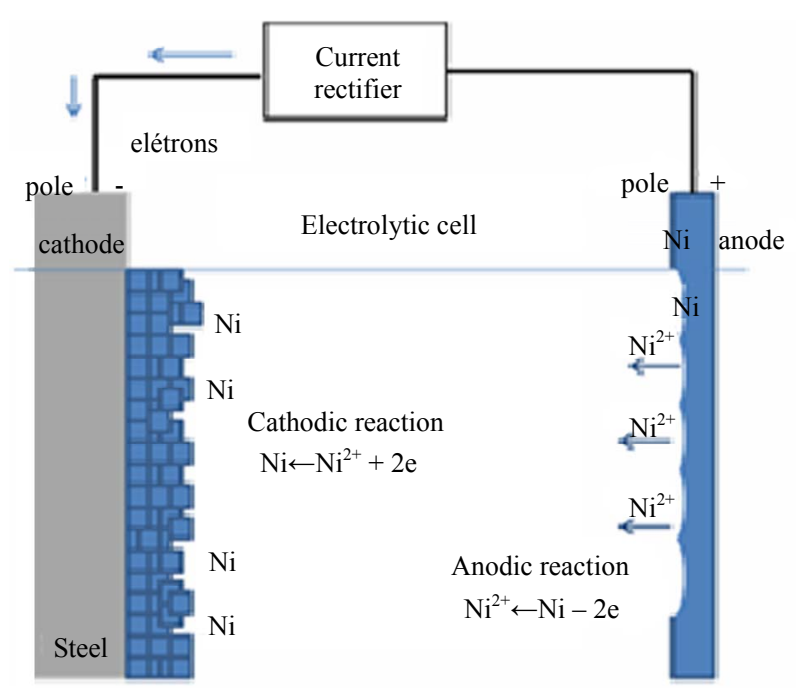

Figure 4. Illustration of electrolytic deposition of nickel on carbon steel. 
Atomic hydrogen $(\mathrm{H})$ formation and adsorption in the metallic surface produced by the reaction of the hypophosphite ion with water.

$\mathrm{H}_{2} \mathrm{PO}_{2}^{-}+\mathrm{H}_{2} \mathrm{O} \rightarrow \mathrm{H}^{+}+\mathrm{H}_{2} \mathrm{PO}_{3}^{2-}+2 \mathrm{H}$

Reduction for atomic hydrogen $(\mathrm{H})$ of $\mathrm{Ni}^{2+}$ ion and hypophosphite $\left(\mathrm{H}_{2} \mathrm{PO}_{2}^{-}\right)$ ion, co-deposition of nickel-phosphorus (NiP) and new adsorption of atomic hydrogen on the deposit of formed $\mathrm{NiP}$

$\mathrm{H}_{2} \mathrm{PO}_{2}^{-}+\mathrm{H} \rightarrow \mathrm{H}_{2} \mathrm{O}+\mathrm{OH}^{-}+\mathrm{P}$

$\mathrm{Ni}^{2+}+2 \mathrm{H} \rightarrow \mathrm{Ni}+2 \mathrm{H}^{+}$

Atomic hydrogen $(\mathrm{H})$ formation and adsorption in the NiP deposit produced by the reaction of the hypophosphite ion with water.

$\mathrm{H}_{2} \mathrm{PO}_{2}^{-}+\mathrm{H}_{2} \mathrm{O} \rightarrow \mathrm{H}^{+}+\mathrm{H}_{2} \mathrm{PO}_{3}^{2-}+2 \mathrm{H}$

New reduction for atomic hydrogen (H) of $\mathrm{Ni}^{2+}$ ion and hypophosphite $\left(\mathrm{H}_{2} \mathrm{PO}_{2}^{-}\right)$ion, co-deposition of nickelphosphorus (NiP) in the NiP deposit.

$\mathrm{H}_{2} \mathrm{PO}_{2}^{-}+\mathrm{H} \rightarrow \mathrm{H}_{2} \mathrm{O}+\mathrm{OH}^{-}+\mathrm{P}$

$\mathrm{Ni}^{2+}+2 \mathrm{H} \rightarrow \mathrm{Ni}+2 \mathrm{H}^{+}$
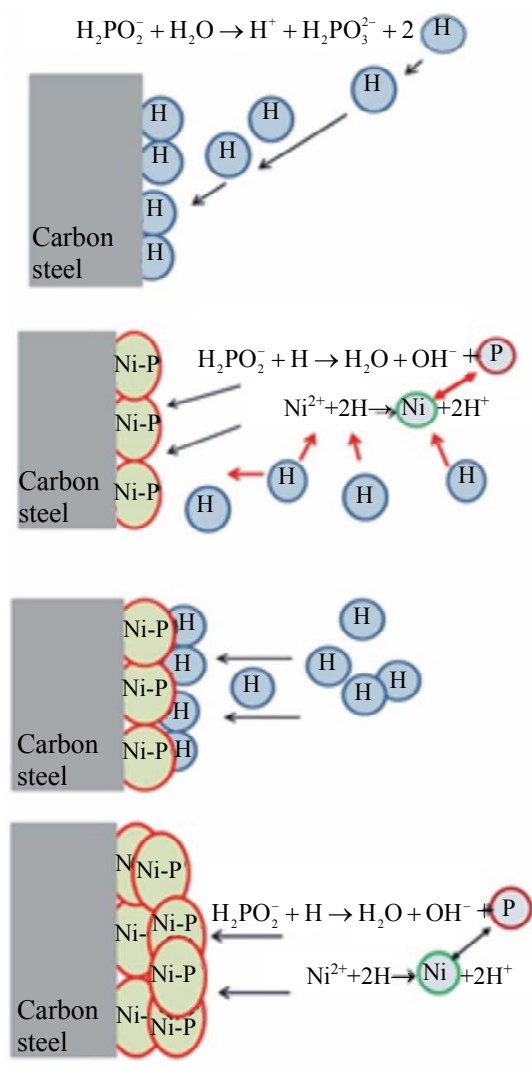

Figure 5. Mechanism of Ni-P layer formation of on carbon steel.

- Co-deposition of nickel and phosphorus on the metal surface.

In the view of Etcheverry [18], the co-deposition of $\mathrm{Ni}-\mathrm{P}$ has the behavior of an alloy, either crystalline or amorphous, depending on the percentage (mass \%) of nickel and phosphorus. Figure 6(a), below, shows the microscopic aspects of Ni-P deposition observed by scanning electron microscopy; Figure 6(b) shows an image taken with an optical microscope.

It is important to note that parallel or unexpected reactions can occur in the bath by reducing the ability of codeposition NI-P coating, such as:

- $\mathrm{H}_{2} \mathrm{PO}_{2}^{-}+\mathrm{H}_{2} \mathrm{O} \rightarrow \mathrm{H}^{+}+\mathrm{HPO}_{3}^{2-}+\mathrm{H}_{2}$ - the hydrolysis of hypophosphite to form molecular hydrogen $\left(\mathrm{H}_{2}\right)$ instead of atomic hydrogen $(\mathrm{H})$, which entails a decrease in the reducing power;

- $2 \mathrm{H} \rightarrow \mathrm{H}_{2}$ - the natural loss of atomic hydrogen $(\mathrm{H})$ reduction capacity;

- $\mathrm{Ni}^{2+}+\mathrm{HPO}_{3}^{2-} \rightarrow \mathrm{NiHPO}_{3}$ - the possibility of nickel ion $\left(\mathrm{Ni}^{2+}\right)$ precipitation in the form of nickel (II) hydrogen phosphite $\left(\mathrm{NiHPO}_{3}\right)$, resulting in the impoverishment of the $\mathrm{Ni}^{2+}$ ion concentration in the bath or, if deposited in the Ni-P coating, it can make a rougher coat.

To avoid this kind of problem, it is essential that substances are present in the bath that act on complexants of

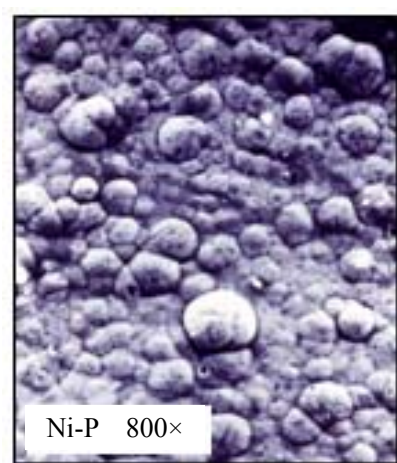

(a)

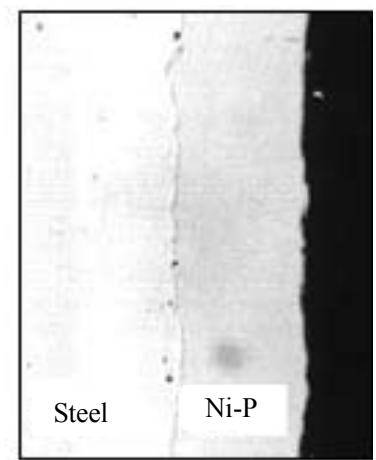

(b)
Figure 6. (a) Scanning electron microscopy (800×); (b) Optical microscopy (200×).

$\mathrm{Ni}^{2+}$ ions (the preventing precipitation). For this, we used organic acid-based formulations, such as tartaric acid, malic acid, succinic acid, adipic acid, hydroxypropionic acid, etc. In addition, the concentration of hydrogen phosphite $\left(\mathrm{HPO}_{3}^{2-}\right)$ ions increases as atomic hydrogen (H) is produced. This concentration should be limited and the occurrence of hydrogen phosphite ion co-deposition along with Ni-P should be monitored as this can lead to a porous coating. Laboratory experiments have shown that the addition of activating substances such as adipic acid, succinic acid, etc. can slow the deposition 
speed of Ni-P and to avoid this kind of problem [17].

In this way, the deposition process is complex and, therefore, the speed of Ni-P deposition on the surface of a part, according to Riedel [17], is preferably a function of the following parameters: temperature, $\mathrm{pH}$, concentration (nickel hypophosphite salts, complexants, activators, stabilizers and contaminants), surface roughness, agitation of the bath and the area/volume relationship of the electroless nickel bath.

According to Riedel [17], the temperature and the $\mathrm{pH}$ are important parameters since, as the deposition temperature and $\mathrm{pH}$ increase, in relation to most baths, an increased speed of deposition is favored, which can create voids or porosity in the deposited layer. The graphs presented in Figure 7 are based on baths containing 15 $\mathrm{g} / \mathrm{L}$ nickel chloride and $10 \mathrm{~g} / \mathrm{L}$ sodium hypophosphite to show this trend.

\section{Ni-P Coating: Specifications and Properties}

The following are some properties of Ni-P coatings
$[17,19]$ based on the nickel and phosphorus levels (Table 1).

For a Ni-P coating applied on carbon steel come meet the adverse conditions of the production of petroleum products, it is essential to adopt a methodology critical inspection "in situ", with due allowance for the manufacturing process of the equipment and the process of deposition based on ISO 4527 [20].

In the critical inspection of process of Ni-P deposition is important to know the various routines comprising the process itself, and must be inspected, among others, the areas of preparation (sandblasting and cleaning chemistry), the process control laboratory (qualified personnel, equipment and assessment procedures), electrochemical baths and the finishing area.

In the actual inspection of the parts should be required to evaluate the following parameters: appearance, uniformity, layer thickness, abrasion, chemical composition, adhesion, porosity and hardness. In addition, with a view to the corrosivity of petroleum, containing $\mathrm{CO}_{2}$ and $\mathrm{H}_{2} \mathrm{~S}$ [21], corrosion tests in order to increase the security of
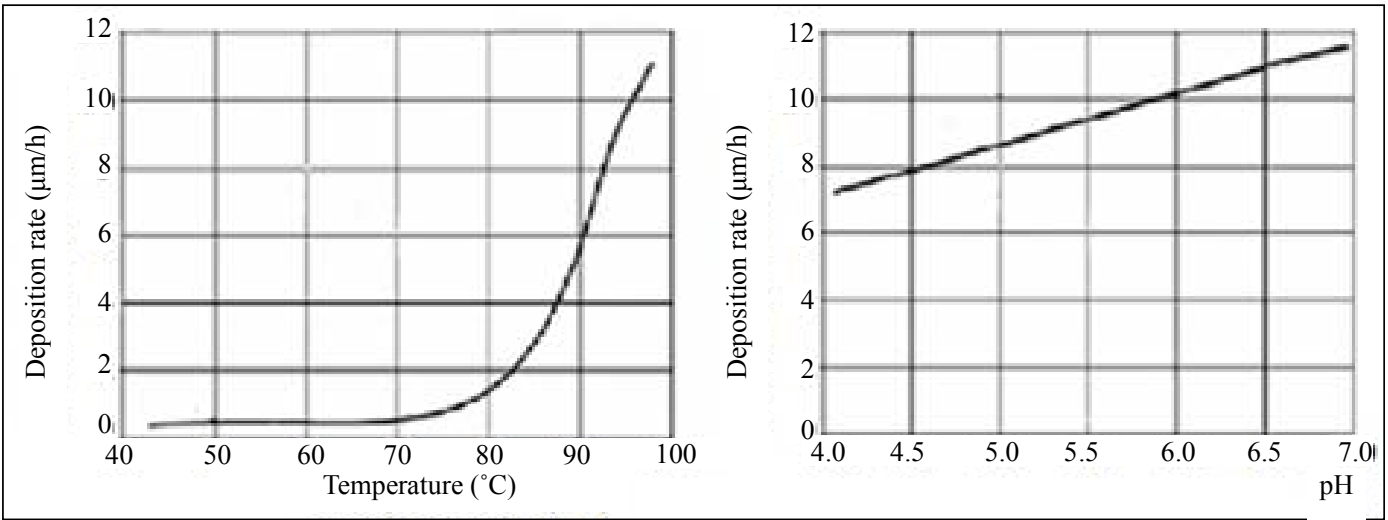

Figure 7. Speed of deposition $(\mu \mathrm{m} / \mathrm{h})$ of $\mathrm{Ni}-\mathrm{P}$ as a function of $\mathrm{pH}$ and temperature.

Table 1. Properties of nickel-phosphorus coatings.

\begin{tabular}{lccc}
\hline \multirow{2}{*}{ Properties } & \multicolumn{3}{c}{ Phosphorus content (\%) } \\
\cline { 2 - 4 } & Low & Medium & High \\
\hline Nickel, \% (mass) & $96-99$ & $92-95$ & $88-91$ \\
Phosphorus, \% (mass) & $1-4$ & $5-8$ & $9-12$ \\
Vickers microhardness without heat treatment, HV & $650-750$ & $500-550$ & $450-500$ \\
Vickers microhardness with heat treatment, HV & $1000-1050$ & $900-950$ & $850-900$ \\
Melting point, ${ }^{\circ} \mathrm{C}$ & 1200 & 890 & 870 \\
Density, $\mathrm{g} / \mathrm{cm}^{3}$ & $8.5-8.7$ & $8.1-8.3$ & $7.7-7.8$ \\
Resistivity, $\mu \Omega / \mathrm{cm}$ & 50 & 70 & 90 \\
Resistance to abrasion & Superior & Very good & Very good \\
Weldability & Good & Regular & Bad \\
\hline
\end{tabular}


the application and the use of Ni-P coating under adverse conditions.

\subsection{Appearance}

On the coated parts visual inspection should not show any defects such as pitting, exfoliations, bubbles, cracks, deposits or failures that may constitute an impediment on the performance of the material.

\subsection{Deposit Thickness and Uniformity}

To work in high aggressive environments are recommended thicknesses ranging from 75 to $125 \mu \mathrm{m}$. The procedure for the determination of the thickness of Ni-P deposit must be specified by the user and/or established by common agreement between the parties, and may be used microscopic methods, magnetic, ultrasonic, etc.

Optical microscopy determines the thickness and uniformity of deposition, however, this method is destructive. To solve this type of problem is allowed the use of a test coupon (testimony) representative for measurement of coating thickness. For a comparison, the micrographs of Ni-P coating applied on carbon steel show in Figure 8, the following are examples of uniformity of layer (Figure 8(a)), while in Figure 8(b) are presented defects occurring during processing of deposition.

\subsection{Chemical Composition}

The corrosion resistance of Ni-P coating depends on the concentration of nickel and phosphorus present in the deposited layer and increasing the phosphorus content improves the anti-corrosion protection. The ISO 4527 [20] standard presents in the Table 2 the chemical composition acceptable for Ni-P coatings. The determination of nickel and phosphorus content in the Ni-P deposit can be made using the following analytical techniques: wet chemical, atomic absorption, x-ray fluorescence, plasma, etc. For the severe conditions of industrial use the phosphorous content shall not be less than $10 \%$ by mass.

\subsection{Porosity}

The porosity of the electroless Ni-P coating is a most important parameter. The deposition of nickel-phosphorus should be free of porosity in order to prevent the corrosive medium contact with the base metal (carbon steel), the corrosive process begins, often through pores or failures. This problem becomes dangerous when the metal is anodic in the relation to $\mathrm{Ni}-\mathrm{P}$ deposit, resulting in a galvanic cell (galvanic corrosion).

In the evaluation of Ni-P coating porosity is used the Ferroxyl Method [20,22]. This method is to place a filter paper on the piece and then applies a mixture of solution $\mathrm{K}_{3} \mathrm{Fe}(\mathrm{CN})_{6}$ - potassium ferricyanide and sodium chloride on the piece during 30 seconds.

The appearance of blue points indicates the porosity and the attack on the base metal (carbon steel) as shown, then, Figure 9. The reactions:

$$
\mathrm{Fe}-2 \mathrm{e} \rightarrow \mathrm{Fe}^{2+}
$$

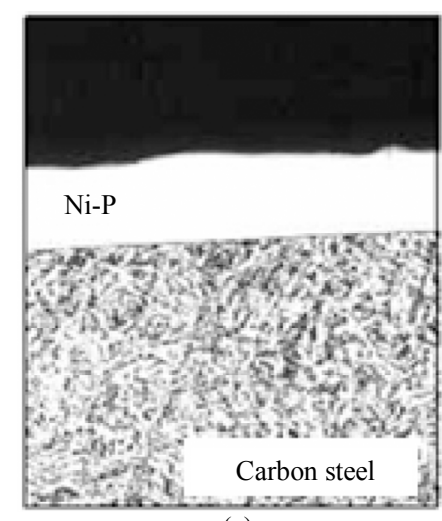

(a)

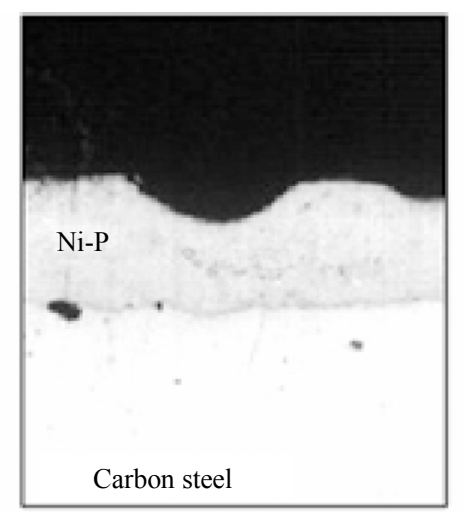

(b)

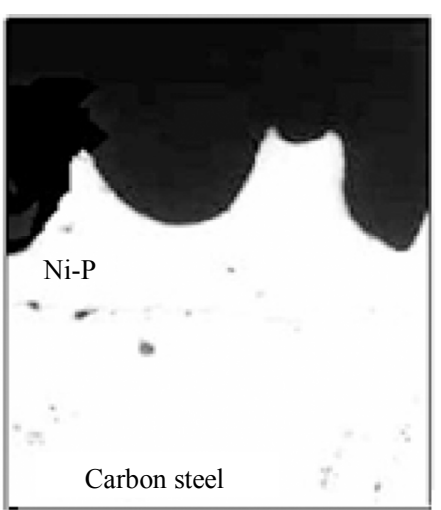

Figure 8. Optic micrographs of Ni-P coating applied on carbon steel: (a) Uniform; (b) Defective layers.

Table 2. Chemical composition of Ni-P deposit [20].

\begin{tabular}{lccr}
\hline \multirow{2}{*}{ Elements } & \multicolumn{2}{c}{ Chemical composition (\% mass) } \\
\cline { 2 - 4 } & Minimum & Maximum & Typical \\
\hline Nickel & 85 & 98 & $88-95$ \\
Phosphorus & 2 & 15 & $5-12$ \\
Other (Al, As, B, Bi, C, Cd, Co, Cr, Cu, Fe, Mn, Nb, Pb, S, Sb, Se ,Si, Sn, V, Zn ) & 0 & 2.0 & 0.05 \\
\hline
\end{tabular}




$$
\begin{aligned}
& 3 \mathrm{Fe}^{2+}+2\left[\mathrm{Fe}(\mathrm{CN})_{6}\right]^{3-} \\
& \rightarrow \mathrm{Fe}_{3}\left[\mathrm{Fe}(\mathrm{CN})_{6}\right]_{2} \text { (blue points) }
\end{aligned}
$$

correspond, to attack the carbon steel and the blue color development on the filter paper placed on the piece or test coupon.

\subsection{Microhardness}

The hardness of Ni-P deposit indicates whether part or not specific heat treatment suffered and usually ranges from 500 to $580 \mathrm{HV}$ (Vickers microhardness). After heat treatment depending on the exposure time and temperature the hardness can vary from 600 to $1100 \mathrm{HV}$. The heat treatment applied to Ni-P coatings shall comply with the directions of the rules in order to minimize the occurrence of cracks or fissures [20,23].

Agarwala \& Agarwala [24] show that the types of baths determine the relationships of the nickel and phosphorus levels in the deposit and the increase of the levels of phosphorus reduces the hardness with and without heat treatment as shown in the Table 3 .

\subsection{Adhesion}

The adhesion of electroless Ni-P to non-conductors is dependent on mechanical keying with associated Van des Waals force. Ni P coatings have good adherence to carbon steel due to the fact that the cohesion of the forces on the metal-base film are often in superior of $140 \mathrm{MPa}$ (20,000 psi). The evaluation of this adhesion is essential and often so that the tests are acceptable, it is indispensable to carry out various tests. These tests are usually comparative, qualitative and quantitative tests are based on an aluminum disk collage on the metallic surface and applying a continuous tension force in aluminum disk until the breakup. However, its implementation depends on the geometry of the piece and its use. Adhesion tests are based on standards: ASTM B 733 [25] and ISO 4527 [20].

\subsection{Abrasion}

Resistance to abrasion is directly related to the phosphorous content, heat treatment and adherence to the surface of the base metal. In general, the increase of the levels of phosphorus and the increase of hardness provided by heat treatment increases the abrasion resistance. Abrasion tests are specified and depending on the specific use of electroless Ni-P coating as recommends ISO 4527 [20].

\subsection{Corrosion}

In evaluating the performance of $\mathrm{Ni}-\mathrm{P}$ coating in different aggressive media are used in laboratory testing and field. In the case of production of oil this Ni-P coating has proven quite attractive, with a view to its good resistance to many corrosive media such as corrosive gases $\left(\mathrm{CO}_{2}, \mathrm{H}_{2} \mathrm{~S}\right)$ and high water salinity, contaminants commonly found in petroleum. However, it is essential to establish two factors are important in corrosion resistance: the phosphorous content which should be more than 10 $\%$ (mass) and the thickness shall not be less than $75 \mu \mathrm{m}$.

Electroless Ni-P coating are not recommended for some corrosive media containing chloride based compounds and ferric sulfate, nitrates, nitrites and ammonium compounds. Laboratory testing to evaluate the performance of electroless Ni-P coating in petroleum with high aggressiveness can be static or dynamic.

The high aggressiveness can be represented by mixes

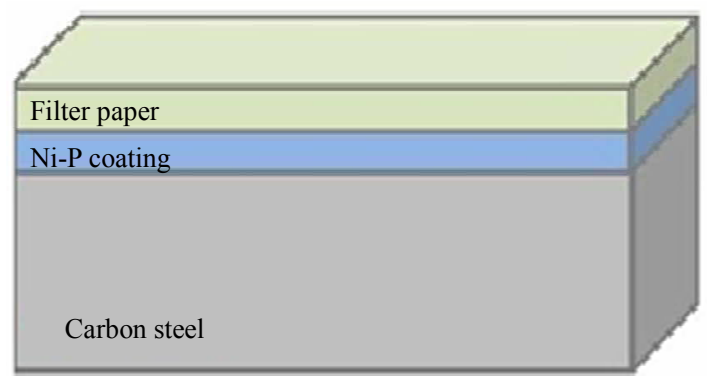

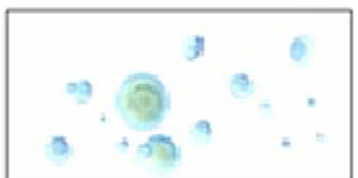

Blue color development on the filter paper

Figure 9. Ferroxyl test applied to determine the porosity of Ni-P deposit on carbon steel.

Table 3. Deposit hardness of Ni-P-carbon steel [24].

\begin{tabular}{ccc}
\hline Phosphorus, \% (mass) & Vickers microhardness (HV) & Vickers microhardness with heat treatment, HV \\
\hline $2-3$ & 700 & 1000 \\
$6-9$ & 550 & 920 \\
$10-12$ & 510 & 880 \\
\hline
\end{tabular}


with salt water and pressurized using mixtures of $\mathrm{CO}_{2}$, $\mathrm{H}_{2} \mathrm{~S}$. The corrosion test can be carried out in a pressurized cell to $70 \mathrm{kgf} / \mathrm{cm}^{2}$. The temperature can range from $25^{\circ} \mathrm{C}$ to $80^{\circ} \mathrm{C}$ and exposure time of 240 hours continuous hours.

\section{Corrosion Testing of Electroless Ni-P Coating}

The carbon steel coupons coated Ni-P, heavy, previously were placed in pressurized containers $\left(70 \mathrm{kgf} / \mathrm{cm}^{2}\right)$ with $300 \mathrm{~mL}$ containing sodium chloride solutions. Sodium chloride solutions used in the test were, respectively, of $3.5 \%, 10 \%, 20 \%$ and $30 \%$ by weight. The tests were run temperature of $25^{\circ} \mathrm{C}$ and for 250 hours of total immersion. The properties of coupons with Ni-P coating are presented below in Table 4.

After the end of the coupons were washed with running water, alcohol and dried with hot air and some coupons were cut to evaluate by optical metallography the corrosive effects of the salt solution.

The tests performed with Ni-P coated coupons did not show noticeable losses in mass and the analysis by optical microscopy did not find attacks on coupons, i.e. it can be considered that the corrosion rates are void.

\section{Concerns or Precautions Regarding Nickel-Phosphorus Coating Applied on Carbon Steel and Used in Extreme Conditions}

Generating ideas of the Principles of Precaution, probably born in the 1970 with the fledgling company's concerns with the ethics, with the environment, with the deterioration of water resources, with the risk of contamination, with the uncertainties of processed foods and the insecurities of the technological applications in various industrial segments.

The term precaution, in the vision of sustainability and of triad industrial safety-environment-workers' health and their descendants, should mean taking measures to protect human health and the environment from possible damage that may happen. This means that the processes

Table 4. Properties of Ni-P coated coupons.

\begin{tabular}{cc}
\hline Properties & Evaluation \\
\hline Phosphorus, \% (mass) & 10.5 \\
Thickness $(\mu \mathrm{m})$ & 75 \\
Porosity & Free \\
Apparent defects & Free \\
Adhesion & Very good \\
Vickers microhardness $(\mathrm{HV})$ & 600 \\
\hline
\end{tabular}

must be safe to avoid or minimize possible disasters, however, in the international area; there are different views that caution has different interpretations, especially when the more industrialized countries impose products and/or obsolete technologies to less developed countries.

In the view of Mainier [26] systems productive, knowledgeable of the risks of industrial manufacturing processes and seeming not to care about the present and not the future, continue to exert strong pressure on the environment, imposing or masking obsolete technologies that include waste, packaging, recycling and toxic waste, themes that often get confused or are linked.

On the interests and economic philosophies and large industrial manufacturing complexes and industrialized countries become fellow-agents of a policy of mutual interest and, in many situations, against the interests of the man himself. In this optic, spills, leaks and contamination with large environmental impact have taken place.

Under the technical point of view can be worrying speed of deposition of Ni-P coating for high thickness in relation to the final cost of the coated part. For example, hypothetically, assuming a thickness $75 \mu \mathrm{m}$ and with reference to three electrochemical baths, respectively, with $3 \mu \mathrm{m} / \mathrm{h}, 10 \mu \mathrm{m} / \mathrm{h}$ and $25 \mu \mathrm{m} / \mathrm{h}$ minimum operating time for these operations would be, respectively, $25 \mathrm{~h}$, $7.5 \mathrm{~h}$ and $3 \mathrm{~h}$.

In a simplistic evaluation the first case will probably have a longer time, forcing the continuous control and systematic and will have higher quality of landfill although the cost is higher when compared to other procedures. At a high speed the possibility of porosity and faults can occur with greater intensity when compared with low layer deposition speed of Ni-P.

Another point that also needs to be evaluated is the life cycle of the piece and its implications in the project as a whole when compared to application of a coating with other leagues more massive and noble and give greater security to the investment.

\section{Conclusions}

On the basis of the facts stated it can be concluded that:

- To ensure the good performance of electroless Ni-P coating is necessary to know the process of electrochemical deposition without external current and secure inspection philosophies during processing and in the final product.

- The quality of Ni-P coating must be supported for constant qualification standards and national and international procedure.

- It is essential to analyze the speed of deposition of coatings on the basis of cost and the possibility of defects to be used in extreme conditions.

- Laboratory testing showed excellent performance for 
Ni-P coatings with $75 \mu \mathrm{m}$ in salt solutions of sodium chloride $3.5 \%$ to $30 \%$ by mass.

\section{REFERENCES}

[1] A. C. R. Wurtz, "On Copper Hydride," Hebdomadaires des Séances de l'Académie des Sciences, Vol. 18, 1844, pp. 702-704.

[2] A. C. R. Wurtz, "On Copper Hydride," Hebdomadaires des Séances de l'Académie des Sciences, Vol. 21, 1845, p. 149.

[3] A. Brenner and G. E. Riddel, "Nickel Plating on Steel by Chemical Reduction," Journal of Research of the National Bureau of Standards, Vol. 37, No. 1, 1946, pp. 3134. http://dx.doi.org/10.6028/jres.037.019

[4] R. N. Duncan, "Performance of Electroless Nickel Coated Steel in Oil Field Environments," Material Performance, Vol. 21, 1983, pp. 28-34.

[5] J. F. Colaruoto, B. V. Tilak and R. S. Jasinki, "Corrosion Charactheristcs of Electroless Nickel Coating of Oil Field Environments," Proceedings of Electroless Nickel Conference IV, Chicago, 22-24 April 1985.

[6] F. B. Mainier, I. M. R. A. Brüning and E. F. Pamplona, "Desenvolvimento de Recipientes para Acondicionamento de Gás Natural Contendo Gases Corrosivos," In: VI Encontro Brasileiro de Tratamento de Superfícies (EBRAT-1989), ABTS, São Paulo, 1987, pp. 66-81.

[7] V. T. Talinn, "In the World of Electroless Nickel," Finishing, Vol. 12, 1988, p. 26.

[8] R. Weil, J. H. Lee and K. Parker, "Comparison of Some Mechanical and Corrosion Properties of Electroless and Electroplated Nickel Phosphorus Alloys," Plating and Surface Finishing, Vol. 76, 1989, pp. 62-66.

[9] F. B. Mainier and M. M. Araújo, "On the Effect of the Electroless Nickel-Phosphorus (Ni-P) Coating Defects on the Performance of This Type of Coating in Oilfield Environments," SPE Advanced Technology Series, Vol. 2, No. 1, 1994, pp. 63-67.

[10] F. Delaunois, J. P. Petitjean, P. Lienard and M. JacobDuliere, "Autocatalytic Electroless Nickel-Boron Plating on Light Alloys," Surface and Coatings Technology, Vol. 124, No. 2-3, 2000, pp. 201-209.

[11] X. Liu, J.-Q. Gao and W.-B. Hu, "Application of Electroless Ni-P Alloys in Electronic Industry," Plating \& Finishing, Vol. 28, No. 1, 2006, pp. 30-34.

[12] D. Baudrand, “Adhesion of Electroless Nickel Deposits to Aluminum Alloys-We Now Have a Better Understanding of the Factors Influencing Adhesion," Products Finishing, Vol. 63, No. 10, 2009, pp. 80-87.

[13] ASTM B-656, “Auto Catalytic (Electroless) Nickel-Phos- phorus Deposition on Metals for Engineering Use," American Society for Testing and Materials, West Conshohocken, 1992.

[14] A. Gould, P. J. Boden and S. J. Harris, "Phosphorus Distribution in Electroless Nickel Deposits," Surface Technology, Vol. 12, No. 1, 1981, pp. 93-102. http://dx.doi.org/10.1016/0376-4583(81)90140-0

[15] J. Bielinski, "The Role of Buffers and Complex Formers in Electroless Nickel Plating," Oberflache Surface, Vol. 25, No. 12, 1984, pp. 423-429.

[16] G. O. Mallory and J. B. Hadju, "Electroless Plating: Fundamentals \& Applications," Cambridge University Press, Cambridge, 1990.

[17] W. Riedel, "Electroless Nickel Plating," Redwood Press Limited, Liverpool, 1991.

[18] B. Etcheverry, "Adhérence, Mécanique et Tribologie des Revêtements Composites NiP_-Talc Multifonctionnels à Empreinte Écologique Réduite," Institut National Polytechnique de Toulouse, Toulouse, 2006.

[19] R. P. Tracy and G. J. Shawham, "Pratical Guide to Using Ni-P Electroless Nickel Coatings," Materials Performance, Vol. 29, No. 7, 1990, pp. 65-70.

[20] ISO-4527, “Autocatalytic Nickel-Phosphorus Coatings, Specification and Test Method," International Organization for Standardization, Geneva, 1987.

[21] F. B. Mainier, G. C. Sandres and R. J. Mainier, "Integrated Management System for In-House Control of Accidental Hydrogen Sulfide Leaks in Oil Refineries," International Journal of Science and Advanced Technology, Vol. 2, No. 9, 2012, pp. 76-84.

[22] ASTM B-656, "Auto Catalytic (Electroless) Nickel-Phosphorus Deposition on Metals for Engineering Use", American Society for Testing and Materials, West Conshohocken, 1992.

[23] ASTM B-578, "Measurements of Micro Hardness of Electroplated Coating," American Society for Testing and Materials, West Conshohocken, 1992.

[24] R. C. Agarwala and V. Agarwala, "Electroless Alloy/ Composite Coatings: A Review," Sadhana, Vol. 28, No. 3-4, 2003, pp. 475-493.

[25] ASTM B-733, "Standards Specifications for Autocatalytic Nickel-Phosphorus Coatings on Metals," American Society for Testing and Materials, West Conshohocken, 1992.

[26] F. B. Mainier, "Uma Visão Crítica das Rotas Industriais de Fabricação de Produtos Químicos Utilizados nos Tratamentos de Água," Congresso de Equipamento e Automação da Indústria Química, Associação Brasileira da Indústria Química (ABQUIM), São Paulo, 1999. 